\title{
Endoscopic full-thickness resection in the rectum closed with PolyLoop-and-clips method using single-channel endoscope
}

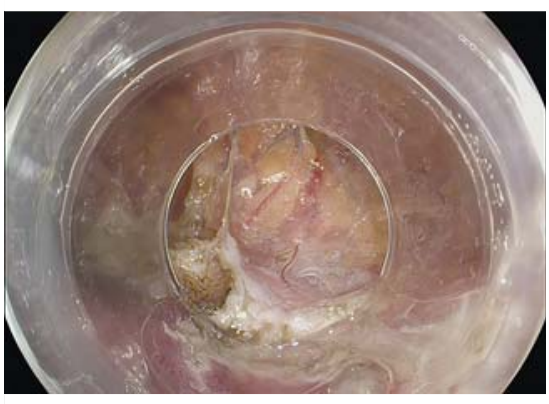

- Fig. 1 Large transmural defect.

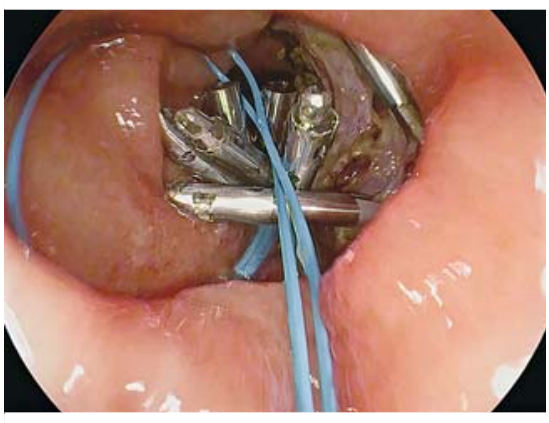

Fig. 2 Closure of the full-thickness defect with a PolyLoop-and-clips method using a single-channel endoscope.

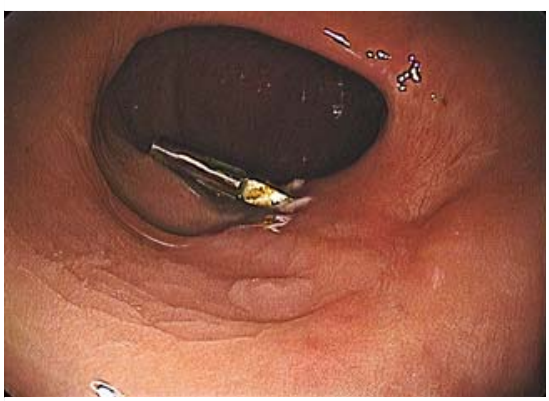

- Fig. 3 Complete re-epithelialization of the mucosa at 6 months.

Endoscopic submucosal dissection (ESD) allows en bloc resection regardless of tumor size. It is an effective but technically demanding procedure, with perforation rates of about $5 \%$ [1]. Nevertheless, the safety profile is adequate, because almost all ESD complications can be managed endoscopically and the risk

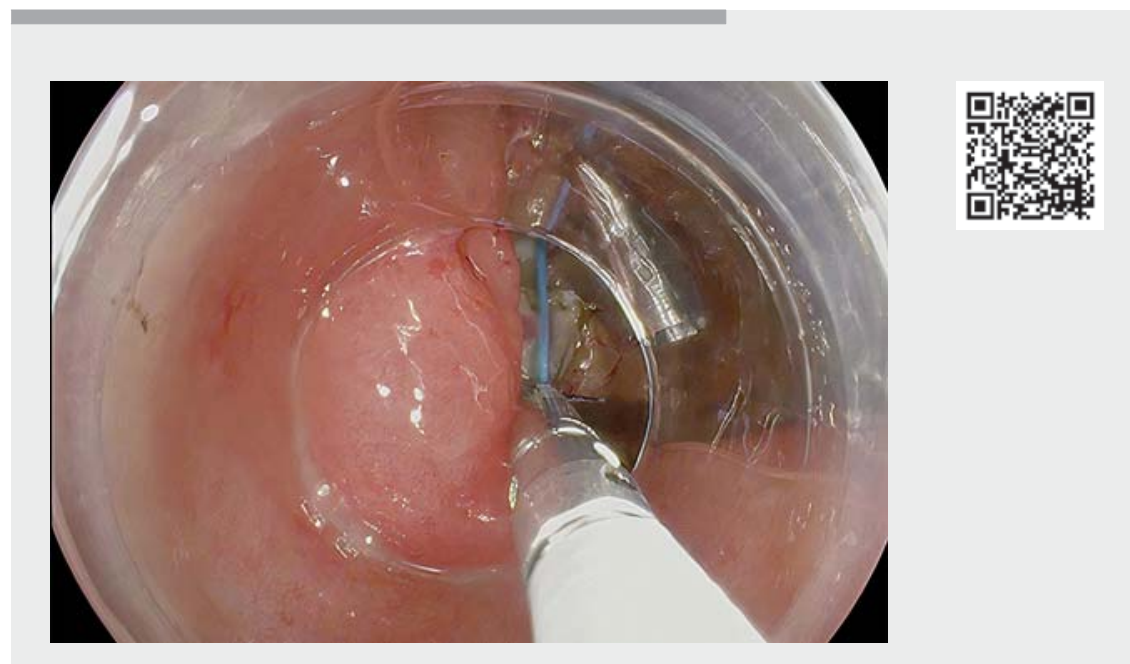

$\checkmark$ Video 1 Endoscopic full-thickness resection in the lower rectum closed with PolyLoopand-clips method using a single-channel endoscope.

of surgery related to post-ESD complications (1\%) is low [2]. The European Society of Gastrointestinal Endoscopy recommends the use of through-the-scope clips for iatrogenic perforations $<10 \mathrm{~mm}$ and consideration of the use of the over-thescope clip for defects $>10 \mathrm{~mm}$, nonetheless larger iatrogenic perforations or failed closure may require surgical repair [3]. Another purse-string suture technique to close the perforations using a dual-channel endoscope with a PolyLoop (Olympus, Tokyo, Japan) and clips has been described [4].

We present the case of a 65-year-old man with a 60-mm laterally spreading granular tumor, nodular mixed subtype, at the lower rectum. No deep submucosal invasion signs were observed. It was decided to perform ESD using a conventional technique owing to the presence of fibrosis. At the end of the procedure, the dissection plane was lost due to the patient's intense breathing movements and Valsalva maneuvers, and full thickness resection was performed ( $\mathbf{F i g . 1}$ ). Bloc resection was completed. Then a PolyLoop attached to a clip inserted through the single-channel endoscope was introduced in parallel. After deploying the first clip, more clips were used to fix the borders of the PolyLoop to the borders of the target area to close ( $\vee$ Video 1 ). The PolyLoop was then closed as well as the full-thickness defect (> Fig.2). There were no complications and the patient was discharged after 24 hours. Final histology was a 67-mm adenoma with high-grade dysplasia (HGD) with negative resection margins. AT 6 months a complete re-epithelialization of the mucosa was observed (> Fig.3). Endoscopic full-thickness resection of large lesions in the rectum might be feasible. Large defects could be closed with a PolyLoopand-clips method using a single-channel endoscope.

Endoscopy_UCTN_Code_CPL_1AJ_2AD

\section{Competing interests}

The authors declare that they have no conflict of interest. 
Edgar Castillo-Regalado ${ }^{1}{ }^{\oplus}$, Carlos Huertas ${ }^{2}$, Leyanira Torrealba ${ }^{2}$, Manuela Hombrados ${ }^{2}$, Montserrat Figa ${ }^{2}$, David Busquets ${ }^{2}$, Hugo Uchima ${ }^{2,3}$ (๑)

1 Gastroenterology Department, Hospital de Mataró, Mataró, Barcelona, Spain.

2 Gastroenterology Department, Hospital Universitari Dr. Josep Trueta, Girona, Spain.

3 Endoscopy Unit, Gastroenterology Department, Hospital Universitari Germans Trias I Pujol, Badalona, Barcelona, Spain.

\section{Corresponding author}

\section{Hugo Uchima, MD}

Endoscopy Unit, Gastroenterology Department, Hospital Universitari Germans Trias, Pujol, Carretera de Canyet s/n, 08916 Badalona, Barcelona, Spain huchima.germanstrias@gencat.cat
[1] De Ceglie A, Hassan C, Mangiavillanoa B et al. Endoscopic mucosal resection and endoscopic submucosal dissection for colorectal lesions: a systematic review. Crit Rev Oncol Hematol 2016; 104: 138-155

[2] Repici A, Hassan C, De Paula PessoaD et al. Efficacy and safety of endoscopic submucosal dissection for colorectal neoplasia: a systematic review. Endoscopy 2012; 44: 137150

[3] Paspatis GA, Arvanitakis M, Dumonceau JM et al. Diagnosis and management of iatrogenic endoscopic perforations: European Society of Gastrointestinal Endoscopy (ESGE) Position Statement. Endoscopy 2020; 52: 792-810

[4] Ryu JY, Park BK, Kim WS et al. Endoscopic closure of iatrogenic colon perforation using dual-channel endoscope with an endoloop and clips: methods and feasibility data (with videos). Surg Endosc 2019; 33: 1342-1348
Bibliography

Endoscopy 2022; 54: E24-E25

DOI 10.1055/a-1352-2356

ISSN $0013-726 \mathrm{X}$

published online 19.2.2021

(c) 2021. Thieme. All rights reserved.

Georg Thieme Verlag KG, Rüdigerstraße 14 , 70469 Stuttgart, Germany

\section{ENDOSCOPY E-VIDEOS}

https:/|eref.thieme.de/e-videos

回回 Endoscopy E-Videos is a free access online section, reporting 回: on interesting cases and new techniques in gastroenterological endoscopy. All papers include a high quality video and all contributions are freely accessible online.

This section has its own submission website at https://mc.manuscriptcentral.com/e-videos 